\title{
Letter to the Editor concerning "Influence of body position and axial load on spinal stiffness in healthy young adults" by Häusler $M$, et al. (Eur Spine J; [2020]: doi:10.1007/s00586-019-06254-0)
}

\author{
Vishal Kumar $^{1} \cdot$ Amit Kumar Salaria ${ }^{1} \cdot$ Naveen Kumar ${ }^{2}$ \\ Received: 28 March 2020 / Revised: 28 March 2020 / Accepted: 22 April 2020 / Published online: 2 May 2020 \\ (c) Springer-Verlag GmbH Germany, part of Springer Nature 2020
}

We read the article titled "Influence of body position and axial load on spinal stiffness in healthy young adults" by Häusler et al. [1] with immense interest and congratulate authors for their immense effort to study, write and conclude on a subject less pondered into. However, there were certain facts and observation which need further discussion and elaboration:

1. There are very limited exclusion criteria in this study like history of backache, infections, fractures, etc. Various other important spinal conditions like asymptomatic inflammatory spondyloarthropathies, asymptomatic congenital disorders (block vertebrae, hemivertebrae) may influence the spinal stiffness.

2. What about the subjects having preexisting disorders of the hip and knee as they have significant impact on the spine biomechanics? Similarly preexisting respiratory and abdominal disorders significantly affect the spinal stiffness [2, 3].

3. Before commenting on the spinal stiffness in various body positions and axial loading, was the coronal and the sagittal balance of the recruits standardized as this could alter the spine biomechanics and muscle recruitment.

4. Was any radiology (X-rays, CT, MRI, etc.) sought before labelling the subjects as normal as they could reveal some important parameters affecting the spine biomechanics and stiffness?

Amit Kumar Salaria

meetamit20salaria@gmail.com

Vishal Kumar

drkumarvishal@gmail.com

1 Department of Orthopaedics, PGIMER, Sector -12,

Chandigarh 160012, India

2 Department of Orthopaedics, YSPGMC Nahan, Nahan, India
5. Was any linear association found between the spinal stiffness and the percentage of additional axial loading? Why only $50 \%$ of the additional axial load was chosen? What if the additional axial load is less or more than $50 \%$ ? Further study is warranted to address these questions.

Funding None.

\section{Compliance with ethical standards}

Conflict of interest All authors declare that there are no potential conflicting interests.

\section{References}

1. Häusler M, Hofstetter L, Schweinhardt P, Swanenburg J (2020) Influence of body position and axial load on spinal stiffness in healthy young adults. Eur Spine J 29(3):455-461

2. Hodges PW, Eriksson AE, Shirley D, Gandevia SC (2005) Intraabdominal pressure increases stiffness of the lumbar spine. J Biomech 38:1873-1880

3. Shirley D, Hodges PW, Eriksson AE, Gandevia SC (2003) Spinal stiffness changes throughout the respiratory cycle. J Appl Physiol 95:1467-1475. https://doi.org/10.1152/japplphysiol.00939.2002

Publisher's Note Springer Nature remains neutral with regard to jurisdictional claims in published maps and institutional affiliations. 